\title{
A INTEGRAÇÃO FINANCEIRA NA ALIANÇA DO PACÍFICO: O CASO DO MILA
}

\author{
FINANCIAL INTEGRATION IN THE PACIFIC ALLIANCE: THE MILA CASE
}

\author{
Julia de Souza Borba Gonçalves ${ }^{1}$
}

\begin{abstract}
Resumo
A Aliança do Pacífico surgiv em 2011 com o propósito de ser um bloco de integração regional que acompanhasse os fluxos do comércio internacional e, consequentemente, que promovesse uma maior vinculação à região ÁsiaPacífico. O bloco se orienta pelo modelo de regionalismo aberto, uma estratégia de integração regional da década de 1990 a qual dá centralidade às ações dos mercados em decorrência da abertura de mercados e liberalização comercial. Dentre seus objetivos, está a dimensão financeira da integração onde há destaque para a integração das bolsas de valores por meio do Mercado Integrado Latino-Americano (MILA). Assim, este trabalho questiona como a dimensão financeira é tratada na Aliança do Pacífico e em que medida o MILA contribuiu para os objetivos estabelecidos pelo bloco de 2011 até 2016. A metodologia apoiou-se na bibliografia especializada sobre regionalismos, integração regional e integração financeira, e sobre a analise qualitativa e indutiva dos documentos de reuniões de Cúpula e de Ministros da Aliança do Pacífico, e dos Comunicados do MILA - as informações coletadas eram a respeito de como a temática da integração financeira era tratada e relação entre o bloco e o organismo. Percebeu-se que houve uma crescente cooperação entre a Aliança do Pacífico e o MILA, colaborando para um dos objetivos estabelecidos pelo bloco.
\end{abstract}

Palavras-chaves: Aliança do Pacífico; regionalismo aberto; integração financeira; MILA; regionalismo latinoamericano.

\begin{abstract}
The Pacific Alliance emerged in 2011 with the purpose of being a regional integration bloc that ensures the international trade flows and a greater linkage to the Asian-Pacific region. The Pacific Alliance ensures the open regionalism, a regional integration strategy of the 1990 s based on market opening and trade liberalization. Regarding the financial dimension of regional integration, a main goal is the integration of stock exchanges through the Latin American Integrated Market (MILA). Therefore, this paper questions how the Pacific Alliance approached the financial aspect of regional integration and to what extent MILA has contributed to the objectives established by the bloc from 2011 to 2016. The methodology used in this paper required the specialized bibliography on regionalisms, regional integration and financial integration, and also the qualitative and inductive analysis of the documents from the Pacific Alliance Summit and the MILA reports - the information collected was about the financial integration and the relationship between these two institutions. We noted that were an increasing cooperation between the Pacific Alliance and MILA, which has collaborated to achieve one of the Pacific Alliance main goals.
\end{abstract}

Key words: The Pacific Alliance; open regionalism; financial integration; MILA; Latin-American regionalisms.

\footnotetext{
${ }^{1}$ Mestranda em Relações Internacionais pelo Programa de Pós-Graduação "San Tiago Dantas". É bolsista CAPES e pesquisadora do Laboratório de Novas Tecnologias em Relações Internacionais (LANTRI) e do Observatório de Regionalismo, ambos vinculados à Rede de Pesquisa em Política Externa e Regionalismos (REPRI). São Paulo, Brasil. Email: juli.borbagoncalves@gmail.com.
} 


\section{INTRODUÇÃO}

Desde o final de 1980, presencia-se o crescimento do sistema capitalista dirigido pelas finanças ou também, o processo de financeirização da economia global. Esta alteração correspondeu ao modo estadunidense de acumulação de capital para o resto do mundo, pautada na liberalização do movimento de capitais e na desregulamentação financeira. A financeirização se refere à participação expressiva dos mercados, atores, ativos e instituições nas operações financeiras de dimensão nacional e internacional, e cujo objetivo primordial é a maximização do valor ao acionista. É, portanto, uma lógica fundamentada na descentralização do Estado e, consequentemente, na regulação pelo mercado (FARHI, CINTRA, 2003; GUTTMANN, 2008).

Os investidores institucionais buscam maximizar os ganhos (diversificação, fluxo de informações) e minimizar os custos (transações). Para tanto, os preços das ações é uma variável chave para que uma instituição financeira organize sua atuação, as quais podem adquirir ações, usá-las como moeda, além de praticar o afrouxamento de normas contábeis e manipulação de dados financeiros. Assim, transformamse nos acionistas principais de grandes empresas em todo o mundo (GUTTMANN, 2008).

Tal como os assuntos relativos à paz, segurança, comércio e coordenação política, a cooperação e/ou integração financeira é um tema presente na agenda de instituições regionais. Na América Latina, esses assuntos estão relacionados com a questão do desenvolvimento nacional; nos últimos anos, a cooperação financeira tem sido centralizada em obras de infraestrutura (fundos regionais e bancos de desenvolvimento) visando à redução de assimetrias. São exemplos desta afirmação: o Fundo para a Convergência Estrutural (FOCEM) do Mercado Comum do Sul (Mercosul), o Fonplata, a Integração da Infraestrutura Regional Sul-Americana (IIRSA), o Banco de Desenvolvimento da América Latina (CAF), o Banco Interamericano de Desenvolvimento (BID) e o Banco Nacional de Desenvolvimento Econômico e Social (BNDES) (SOUZA-SANTOS, 2013).

A Aliança do Pacífico, surgida em 2011 e com o objetivo de promover a integração regional segundo o regionalismo aberto da década de 1990, inclui em seus objetivos o aspecto comercial, a integração produtiva, estrutural e financeira. Em relação a esta última, um objetivo específico é a integração das bolsas de valores dos países no âmbito da instituição chamada Mercado Integrado LatinoAmericano (MILA). Este objetivo foi sinalizado logo no primeiro documento decorrente da primeira Cúpula da Aliança do Pacífico e tem sido reiterado nas Cúpulas seguintes.

Portanto, é de interesse do trabalho abordar como a dimensão financeira foi tratada na Aliança do Pacífico, tendo em conta a existência do MILA e como este contribuiu para os objetivos estabelecidos pelo bloco de 2011 até 2016.

Este trabalho se propõe a analisar a questão sob a ótica das Relações Internacionais, renunciando o uso de metodologias quantitativas advindas do campo da Economia. Neste último, por exemplo, já foram feitos trabalhos analisando o desempenho das bolsas de valores e o retorno de capitais do MILA ao 
decorrer dos anos (DURRANI, PICA, 2016; GUILLERMO, 2016). Não é de interesse deste trabalho fazer uma análise similar, ainda que seja interessante utilizar os resultados daqueles, mas fazer uma análise que se aproxime aos estudos sobre Integração Regional e Regionalismos. Ademais, cabe mencionar que foram poucos trabalhos produzidos sobre o tema nesta perspectiva (LERAUL, 2016), além de serem escassos os dados qualitativos sobre o MILA, restringindo-se à informes mensais elaborados pela própria instituição (Mila News) - inclusive, os dados quantitativos foram retirados majoritariamente de outras fontes, tal como o Economática² e o BID, do que do próprio site da instituição.

Nesse sentido, o trabalho se propõe a fazer uma análise da evolução das discussões sobre integração financeira na Aliança do Pacífico, ainda que de maneira inicial e não tão aprofundada devido aos fatores anteriormente mencionados. Como o propósito deste trabalho é aproximar o tema das Relações Internacionais, a metodologia utilizada foi baseada na leitura da bibliografia especializada em Integração Regional e Regionalismos Latino-Americanos e na análise qualitativa e indutiva da integração financeira na Aliança do Pacífico, a fim de se chegar a conclusões iniciais e que possam servir ao aprofundamento ou à revisão das mesmas. Os documentos analisados foram os documentos finais das Cúpulas da Aliança do Pacífico e os documentos informativos do MILA News, do período de 2011 a 2016, a fim de estabelecer se houve um encontro institucional entre aqueles.

Na primeira seção, busca-se estabelecer uma relação entre teorias de integração regional, integração econômica e integração financeira, com o objetivo de evidenciar os processos que ocorrem em cada um e verificar se há pontos em comum. Na segunda parte, objetiva-se explicar a Aliança do Pacífico a partir de sua proposta de integração regional e o tipo de regionalismo fomentado pelo bloco. Na terceira e quarta seção, examina-se, desde uma perspectiva cronológica, a evolução dos assuntos financeiros tratados pelo bloco com respeito à temática de integração das bolsas de valores e a constituição do MILA, visando, por fim, identificar em que medida houve a participação do MILA no andamento dos trabalhos propostos pelo bloco.

\section{Integração regional e integração financeira: da teoria à prática na América Latina}

O regionalismo é um conceito que expressa o conjunto de iniciativas de integração e/ou cooperação econômica e política em um âmbito espacial determinado. A integração regional diz respeito a um processo específico que envolve dois aspectos fundamentais: a localidade territorial e o próprio processo em si. É um processo fundamentalmente de intensificação e abrangência das relações entre atores que pode levar à criação de governança regional através da constituição de instituições políticas (HOFFMAN, HERZ, 2004; BRICEÑO RUIZ, 2014).

2 Disponível em: https://economatica.com/. Acesso em: 23 fev. 2018. 
Ernst Haas foi um teórico que examinou o desenvolvimento da União Europeia e cujos trabalhos foram um marco para as teorias de integração regional ${ }^{3}$. No livro "The Uniting of Europe", Haas (1958) define os tipos ideais de "comunidade política", "integração política" e "supranacionalidade" para explanar como a integração regional é um processo de unificação de diversos grupos em torno de decisões coletivas.

A comunidade política é definida como uma condição na qual grupos e indivíduos mantêm lealdade às instituições políticas centrais (núcleo) mais do que a qualquer outra autoridade política, por um período longo, confiando suas expectativas e satisfações naquela - como por exemplo, o Estado-Nação enquanto núcleo central. Segundo o autor, essa definição foi elaborada a partir da identificação de padrões de comportamento habituais (HAAS, 1958).

Ademais, Haas (1958) cita o nacionalismo como elemento importante nessa definição, à medida que se torna uma realidade de valores e de demandas compatíveis àquela agrupação de pessoas, ao mesmo tempo em que a separa de outras comunidades políticas.

A integração política, por sua vez, é conceituada como um processo que depende da condição anterior (comunidade política) e da percepção de interesses e de valores pelos atores participantes do processo em questão; a integração ocorre quando grupos e indivíduos são persuadidos a serem leais a um novo núcleo, cujas instituições possuem jurisdição sobre os Estados-Nação pré-existentes. O resultado final é a configuração de uma nova comunidade política sobreposta às demais (HAAS, 1958).

Portanto, a integração é um processo onde há a transferência de competências nacionais para uma entidade supranacional envolvendo aspectos econômicos, sociais, culturais e políticos. A supranacionalidade é a existência de autoridades governamentais próximas do arquétipo de Federação4 , porém, diferente dessa, é capaz de implementar decisões independentemente das partes (HAAS, 1958).

Quanto à integração econômica especificamente, este é um processo que segue a mesma lógica elaborada por Haas (1958), mas que envolve etapas ligadas ao comércio internacional. A integração se difere da cooperação em termos quantitativos e qualitativos; um tratado comercial entre Estados é entendido como uma forma de cooperação, enquanto a decisão de eliminar as tarifas comerciais entre as partes é um ato de integração econômica (BALLASA, 1961).

Bela Balassa (1961) ao examinar este processo específico, atesta que a integração econômica pode ser um processo e um "estado da coisa" (state of affairs): no primeiro, a integração diz respeito às medidas de abolição de discriminações entre unidades econômicas de diferentes Estados; no segundo, diz respeito a um estado de ausência de formas de discriminação entre economias nacionais.

\footnotetext{
3 Em sua obra, Haas destacou que "International relations in contemporary western Europe provide a living laboratory of these processes at work" (p. 4, 1958) e citou como exemplos a Organização para a Cooperação Econômica Europeia, Conselho Europeu, Comunidade do Carvão e Aço Europeu, e União da Europa Ocidental.

4 Uma Federação é definida como uma forma de governo na qual a soberania ou o poder político é dividido entre os governos centrais e locais, para que as partes mantenham a independência entre si (HAAS, 1968).
} 
Dessa forma, a integração econômica sugere etapas graduais. Uma Zona de Livre Comércio é o primeiro estágio desse processo, onde as tarifas são abolidas; uma União Aduaneira envolve a supressão de discriminações em relação ao movimento de mercadorias no interior da União ao passo que se estabelece uma Tarifa Externa Comum em relação a terceiros; um Mercado Comum é um estágio elevado da integração econômica, pois as barreiras de comércio e movimentos de fatores de produção são eliminadas; uma União Econômica envolve aspectos do Mercado Comum com um grau de harmonização econômica, monetária, fiscal, social e de adoção de políticas anticíclicas; por último, uma integração econômica total pressupõe a unificação de todos os elementos anteriormente mencionados e requer a configuração de uma autoridade supranacional, cujas decisões são aceitas pelos Estados-membros (BALASSA, 1961).

O aspecto econômico da integração pode considerar a dimensão comercial e a financeira. A integração financeira, por sua vez, não é tratada a partir de uma única abordagem na literatura acadêmica, podendo ter significados diversos. Pode significar uma expansão dos fluxos de capitais estrangeiros e a ampliação dos investimentos estrangeiros em ativos financeiros domésticos; pode estar relacionada diretamente com a abertura financeira, que leva a uma maior integração com o sistema financeiro global; e pode, também, significar um movimento dos mercados de capitais nacionais em direção à unificação, ou seja, à criação de um mercado único. De modo geral, a integração financeira é o estreitamento dos laços entre os mercados, os investidores e as instituições financeiras de diferentes países (MARTINS, 2016).

Conforme argumentado acima, Biancareli (2009) sustenta que a dimensão financeira da integração regional é um assunto menos estudado e debatido em relação aos demais aspectos daquele processo. Disto decorrem duas dificuldades: por um lado, a ausência de um trabalho teórico-empírico e de instituições internacionais que tratem de questões relativas às peculiaridades de cada região; e por outro, a integração financeira se torna um processo amplo de abolição de controle sobre o fluxo de capital de uma única economia em direção ao sistema financeiro internacional como um todo.

Desta forma, destaca-se um ponto em comum entre os processos de integração regional, econômico e financeiro: são processos que de modo geral que buscam eliminação de barreiras sobre determinado tema em direção a uma maior aproximação entre as partes, os quais podem resultar em acordos ou em instituições supranacionais de caráter decisório ou não.

Contudo, destaca-se que as teorias que se propõem a analisar a integração regional foram formuladas a partir de experiências europeias, o que acaba gerando dificuldades para analisar o caso de países fora da realidade daquele continente (MARIANO, 2004).

Ainda que a integração regional latino-americana tenha como sua força articuladora o liberalismo enquanto doutrina econômica, a constituição de órgãos decisórios supranacionais tem sido um desafio para os países latino-americanos. Estes países compartilham uma característica em comum: foram países marcados pela luta para consolidar sua soberania interna. Desta forma, a decisão de conceder soberania externa, ainda que gradualmente, é uma tarefa praticamente impossível (CORREDOR, VÉLEZ, 2014). 
Outra característica é que esquemas de integração regional na América Latina têm sido marcados pelo que postulam as teorias intergovernamentalistas da integração regional: os Estados agem de maneira racional quanto à maximização dos ganhos individuais ao menor custo, o que leva as instituições supranacionais serem vistas como instâncias nas quais governos nacionais buscam manter o controle dos processos políticos e dos resultados através da barganha. Desta maneira, o caráter intergovernamental dos esquemas de integração latino-americanos reforça o presidencialismo forte na diplomacia e a cultura política nacionalista da região (MARIANO, 2004; SANAHUJA, 2017).

A construção do Mercosul é um exemplo disto. Em 1991, os presidentes de Argentina, Brasil, Uruguai e Paraguai assinaram o Tratado de Assunção, o qual criou formalmente o Mercosul, e em 1994 assinaram o Protocolo de Ouro Preto, que definiu a estrutura institucional e estabeleceu as atribuições e o sistema de tomada de decisões de seus órgãos principais (MINISTÉRIO DAS RELAÇÕES EXTERIORES, [2018]).

Contudo, em 1994 se produziu o primeiro choque entre o propósito original, a constituição de um Mercado Comum, e a viabilidade de implementá-lo diante a necessidade do aprofundamento prévio do processo; no final, se optou por cumprir as decisões relativas à institucionalização do bloco, enfatizando a característica intergovernamental dos órgãos do mesmo e a tomada de decisão por consenso e com a presença de todos os Estados (ALVAREZ, 2011).

Na América do Sul, uma das iniciativas de integração financeira que ganhou bastante repercussão se deu no âmbito da União Sul Americana de Nações (Unasul), com a proposta de criação do Banco do Sul como um banco voltado para o desenvolvimento, com o objetivo de financiar os grandes projetos (que requerem aporte de grande capital) e também as políticas públicas voltadas ao aspecto social. No entanto, um dos desafios do Banco tem sido o consenso em torno dos mecanismos operacionais e a vontade política para levar o projeto adiante, tal como a ausência de ratificação por parte do Brasil e do Paraguai ${ }^{5}$ (CARVALHO et al, 2010).

Contrariando a lógica de integração que se seguiu durante a primeira década do século XXI - o regionalismo pós-liberal e pós-hegemônico (VEIGA, RÍOS, 2007; SANAHUJA, 2009; TUSSIE, RIGGIROZZI, 2012) - e que resultou no relançamento do Mercosul, na criação da Unasul, da Aliança Bolivariana (ALBA) e da Comunidade dos Estados Latino-Americanos e Caribenhos (Celac), a Aliança do Pacífico emergiu como novo bloco de integração regional cuja proposta resgata a noção de regionalismo aberto (CEPAL, 1994), que vigorou na década de 1990. Sua proposta de integração financeira concentra-se na integração das bolsas de valores no âmbito do MILA.

\section{Aliança do pacífico e seu modelo de integração regional}

5 Disponível em: http://g1.globo.com/economia/noticia/2016/08/banco-do-sul-chama-brasil-e-paraguai-para-ratificar-suafundacao-2016082620000439939g.html. Acesso em: 22 fev. 2018. 
A Aliança do Pacífico foi uma iniciativa peruana criada em 28 de abril de 2011, da qual fazem parte Chile, Colômbia, México e Peru. Tal como consta em seu site ${ }^{6}$, os objetivos da Aliança do Pacífico são: a) construir de maneira participativa uma área de integração profunda para avançar progressivamente em direção à livre circulação de bens, serviços, capitais e pessoas; b) impulsionar um maior crescimento, desenvolvimento econômico e competitividade das economias de seus integrantes visando o bem-estar, a superação da desigualdade socioeconômica e impulsionar a inclusão social de seus habitantes; c) converter-se em uma plataforma de articulação política, integração econômica e comercial, e projeção ao mundo com ênfase na região Ásia-Pacífico. Em 2012, os presidentes assinaram o Acordo Marco, o qual é o tratado constitutivo do bloco, sinalizando os compromissos, diretrizes, regras decisórias ${ }^{7}$ e requisitos para tornar-se membro efetivo do mesmo.

O bloco se organiza a partir do seguinte organograma: Cúpulas presidenciais, seguido da Presidência Pro-Tempore; Conselho de Ministros; Grupo de Alto Nível e Grupos Técnicos; e os Estados Observadores (ALIANZA DEL PACÍFICO, [2018]).

A Aliança do Pacífico busca consolidar-se nos moldes da iniciativa Foro del Arco del Pacífico LatinoAmericano de 2007: esta foi uma iniciativa que buscou agrupar os países que já mantinham tratados de livre comércio com os EUA e que eram favoráveis à ideia de uma integração mais liberal; no entanto, essa iniciativa sofreu um impasse em decorrência das mudanças de governo em alguns países, como Equador e Nicarágua, e da desaceleração da economia estadunidense, perdendo força no período que se seguiu (BRICEÑO RUIZ, 2014; TABÍO, 2014). No lugar, ganharam força as iniciativas que visavam à coordenação política na região: ALBA, Unasul e Celac.

O regionalismo aberto proposto pela Aliança do Pacífico resgata a estratégia regionalista da década de 1990, que prega a liberalização comercial, abertura econômica e a centralidade das ações do mercado a fim de promover maior competitividade. O regionalismo aberto foi uma estratégia de adaptação ao processo de globalização econômica, de modo que os acordos regionais de livre-comércio pudessem fomentar as vantagens competitivas diante da economia global pós-guerra fria (CEPAL, 1994i SERBÍN, 2014; SANAHUJA, 2017).

Tanto a formação do bloco quanto o modelo de regionalismo devem ser entendidos como resultados das opções políticas dos presidentes dos Estados-membros da Aliança do Pacífico à respeito do modelo de desenvolvimento pautado pela abertura comercial. Os países da Aliança do Pacífico, no contexto de sua formação, tiveram à frente dos governos partidos políticos entendidos sob o conceito de Nova Direita ${ }^{8}$, cujo traço marcante é a orientação econômica de cunho neoliberal, que se expressa na opção de estabelecer Tratados de Livre-Comércio com grandes potências a fim de aproximar-se delas. Ademais, destaca-se o forte apoio e envolvimento do empresariado na formação e no próprio desenvolvimento da Aliança do Pacífico, o qual incidiu na decisão de que um país se tornaria membro desse

\footnotetext{
${ }^{6}$ Disponível em: https://alianzapacifico.net/que-es-la-alianza/\#la-alianza-del-pacifico-y-sus-objetivos. Acesso: 14 out. 2017.

7 Estabeleceu-se que todas as decisões e acordos aprovados no âmbito da Aliança do Pacífico devem ser consensuais.

${ }^{8}$ Em seu artigo, Hendler (2015) utiliza os conceitos propostos pelo economista Bresser-Pereira de Nova Esquerda, Velha Esquerda e Nova Direita para caracterizar as correntes políticas e os projetos de integração regional.
} 
bloco se tivesse pelo menos um Tratado de Livre-Comércio com cada membro (SERRANO; GALARRETA, 2013; HENDLER, 2015).

Como consequência dessa estratégia comercial, os países desse bloco mantêm relações bilaterais políticas e econômicas fortes com os EUA e, recentemente, com a China (HENDLER, 2015). Justamente pelas preferências políticas-comerciais, o surgimento da Aliança do Pacífico gerou discussões acerca da contraposição aos blocos já existentes e, consequentemente, da fratura da integração regional nos eixos Atlântico-Pacífico ${ }^{9}$. A Aliança do Pacífico faria uma contraposição aos valores antiimperialistas da ALBA e à centralidade conferida ao Estado enquanto promotor do desenvolvimento econômico do Mercosul (BUELVAS, ALEGRÍA, VÉLEZ, 2014; SANAHUJA, 2017).

A aproximação com a região Ásia-Pacífico, um dos pilares do bloco, justifica-se pela ascensão econômica da Ásia naquele período e o peso da China na política internacional contemporânea. A China, nos últimos anos, tem fortalecido sua presença na América Latina e sua aproximação não se dá apenas no campo comercial, mas também financeiro, político e cultural. Como evidências dessa aproximação, destacam-se a decisão chinesa de se tornar membro observador da Organização dos Estados Americanos (OEA) e de integrar o BID, a criação dos Institutos Confucio nos países latino-americanos e o aumento das visitas realizadas por mandatários chineses àqueles (PORRAS, 2014; HENDLER, 2015).

Desde sua criação, estes foram principais alcances destacados pelo bloco: a entrada em vigor do Protocolo Adicional do Acordo Marco, em $1^{\circ}$ de maio de 2016, que eliminou 92\% de suas barreiras tarifárias e estabeleceu o prazo de até 2030 para a eliminação dos $8 \%$ restantes; a criação da Plataforma de Mobilidade Acadêmica e Estudantil; o estabelecimento de duas oficinas comerciais conjuntas (Turquia e Marrocos) e de embaixadas compartilhadas (Gana); a criação do Programa de Férias e Trabalho; e a consolidação do Mercado Integrado Latino Americano (MILA).

No entanto, ainda que tenha tido alcances concretos e que conste em seus documentos que o bloco trabalha com o intuito de alcançar a integração profunda, não se tem visto interesse por parte dos membros da Aliança do Pacífico de que o bloco avance do estágio de Zona de Livre Comércio em direção a uma União Aduaneira ou a um Mercado Comum (CORREDOR; VÉLEZ, 2014).

Assim como abordado na primeira seção, a integração regional pode levar ou não à criação de instituições de cunho supranacional. Do mesmo modo, em matéria de integração financeira é recorrente o surgimento de um processo de expansão dos negócios sem necessariamente ocasionar na construção de instituições e na unificação das estruturas de mercado (MARTINS, 2016). No caso da Aliança do Pacífico, percebeu-se que não ocorre um aprofundamento da integração financeira que resultasse na criação de uma instituição supranacional, mas sim uma "simbiose" do bloco e um organismo já existente: o MILA.

\footnotetext{
9 No caso da Unasul, como todos os países da Aliança do Pacífico estão nesse bloco, é difícil estabelecer uma relação entre contraste entre os mesmos. Contudo, é possível cogitar que a Aliança do Pacífico, ao fomentar o estreitamento das relações com a região Ásia-Pacífico como parte de seus objetivos, possa permitir ainda mais a influência asiática na região, trazendo implicações à Unasul à longo prazo.
} 


\section{A evolução da integração financeira nos documentos oficiais da Aliança do Pacífico}

A primeira reunião da Aliança do Pacífico ocorreu durante o mês de abril de 2011 em Lima, no Peru, a convite do ex-presidente peruano, Alan García. Na ocasião, foram ressaltados os avanços de cada país em matéria de desenvolvimento e crescimento econômico inclusivo, e o compromisso de privilegiar a integração como instrumento efetivo para melhorar o desenvolvimento social e econômico da população de cada país - com destaque para a importância dos acordos de livre-comércio a fim de contribuir e aprofundar a integração de suas economias (ALIANZA DEL PACíFICO, 2011a).

Os presidentes também indicaram os temas a serem trabalhados nesta primeira etapa, dentre os quais estavam a livre circulação de pessoas de negócios; a facilitação do comércio e cooperação aduaneira; e a possibilidade de integração das bolsas de valores (ALIANZA DEL PACíFICO, 2011a).

Desde então, ao analisar os documentos finais ${ }^{10}$ de cada Cúpula da Aliança do Pacífico, percebese que a integração de bolsas de valores no âmbito do Mercado Integrado Latino-Americano (MILA) é uma questão recorrente da agenda de integração financeira do bloco.

Na reunião seguinte, em relação às questões financeiras, os presidentes destacaram os trabalhos a serem feitos em matéria de serviços e capitais, focando principalmente na questão do aumento dos investimentos, no entanto, sem retornar a mencionar a integração das bolsas de valores (ALIANZA DEL PACÍFICO, 2011b).

Os presidentes da Aliança do Pacífico voltaram mencionar a integração de bolsas de valores na Cúpula de Paranal (2012), para destacar o processo de incorporação da Bolsa Mexicana de Valores (BMV) em uma instituição já existente: o MILA. Em relação a outras questões financeiras, destacaram os trabalhos desenvolvidos pelos grupos ProExport, ProChile, ProMex, Prolnversiones ${ }^{11}$ para promover os produtos e serviços da região nos mercados internacionais, a fim de atrair investimentos externos.

Foi na Cúpula de Punta Mita (2014) que, por fim, foi anunciada a incorporação plena da BMV ao MILA, o que permitiu que a partir de então se pensasse numa atuação conjunta das duas instituições no que diz respeito à integração financeira, uma vez que os quatro países da Aliança do Pacífico estavam operando também no MILA.

\section{A relação entre MILA e Aliança do Pacífico na integração financeira regional}

Em maio de 2011, um mês após o anúncio do ex-presidente peruano sobre a constituição de um novo bloco regional e seus objetivos (dentre eles a integração de bolsas de valores), entra em operação o MILA: um organismo privado voltado para a integração de mercados de ações a fim de fomentar o desenvolvimento dos mercados de valores locais e a geração de negócios financeiros entre os participantes

\footnotetext{
${ }^{10}$ Os documentos finais ou "Declaraciones de (nome da cidade que sedia a reunião Cúpula da Aliança do Pacífico)" também tem caráter instrutivo.

${ }^{11}$ Instituições dedicadas ao fomento de exportações e captação de investimentos estrangeiros
} 
dos países membros, de maneira que pudessem oferecer uma infraestrutura competitiva e maior oferta de produtos para investidores locais e estrangeiros (MILA, [2017]).

O MILA decorre do acordo firmado em 2009 entre a Bolsa de Comércio de Santiago, a Bolsa de Valores da Colômbia e a Bolsa de Valores de Lima. Estas bolsas iniciaram o processo de criação de um mercado regional para a negociação de títulos de renda variável dos três países (MILA, [2017]). O MILA funciona como uma ferramenta facilitadora das operações financeiras internacionais, sendo este atualmente "o primeiro mercado da América Latina em número de empresas integradas, o segundo em tamanho de capitalização de stocks e o terceiro em volume de negociação" (PATRÍCIO, 2016, p. 143).

A criação de um mercado regional busca estabelecer um espaço para que acionistas dos três países possam comprar e vender ações dos mercados de ações através de um intermediário local. A integração dos mercados de ações do MILA propõe um sistema no qual a autonomia e autoridade dos reguladores mobiliários nacionais são preservadas; ou seja, não implica na integração societária das mesmas (ALAMOS, VÁSOUEZ-PÁRRAGA, ARRIAGADA, 2015; LERAUL, 2016).

A ideia de constituir um mercado regional tem como objetivo a melhora da liquidez ${ }^{12}$ do Mercado Integrado para então alcançar a promoção conjunta dos mesmos, a visibilidade internacional da região como destino de investimento e a expansão regional no MILA ${ }^{13}$.

O MILA oferece a possibilidade para que os intermediários estejam interconectados e atuando sob as normas homologadas, cujas compensações e liquidação ocorrem sem duplicidade de processos em cada país, além de manter a custódia de valores nos mercados de origem com completa interconexão entre depósitos. Assim, o MILA oferece um ponto de acesso único para investidores fora da região e a possibilidade de ter um portfólio diversificado (MILA, [2017]).

Em um estudo realizado por Romero, Ramírez e Guzmán (2013), os autores argumentam que houve integração entre Chile, Peru e Colômbia, mas que o retorno dos riscos dos mercados em cada país foi diferente ao retorno do MILA. Ademais, argumentam que, ainda que a integração financeira promova benefícios, tais como diversificação e ampliação dos ativos negociados em cada mercado local (como visto no caso da Colômbia e Peru pelo estudo) por outro lado, aquela também leva os mercados do Chile a estarem submetidos as mesmas condições de riscos, o que implica na diminuição da diversificação à longo prazo.

O MILA foi mencionado na Cúpula de Paranal (2012) apenas para destacar que o grupo estava avançando em matéria de integração de bolsas de valores com o processo de incorporação plena da BMV. Um ano antes da sua incorporação de fato ao MILA, o mercado contava com 600 empresas negociadas, sendo o segundo em capitalização bursátil e o terceiro em negociação e operações com renda variável da América Latina.

\footnotetext{
${ }^{12}$ Liquidez é um conceito que expressa a facilidade de converter ativos em dinheiro.

13 Disponível em: http://www.mercadomila.com/home/quienessomos. Acesso em: 06 jun. 2017.
} 
A Cúpula de Punta Mita (2014) foi o marco para que o MILA passasse a ser repercutido como instituição ligada à Aliança do Pacífico e não mais como uma instituição à parte daquela, e cujos avanços fossem demonstrados como avanços do próprio bloco. Com a inclusão da BMV, o S\&P Dow Jones ${ }^{14}$ logo anunciou o lançamento da S\&P MILA Pacific Alliances Indices em substituição ao S\&P Mila Andean 40 Index, reforçando a ideia de que o organismo agora era vinculado ao bloco regional. A criação do índice decorre da necessidade de se medir o desempenho do mercado de ações (MILA, 2014).

Em 2015 - após a incorporação plena da BMV - o MILA lançou uma nota oficial para indicar os avanços de seus trabalhos ao longo dos quatro anos de existência: a instituição se consolidou como maior plataforma bursátil da região, com uma capitalização de bolsas de 940 bilhões de dólares e mais de 740 empresas negociadas, superando a Bovespa (MILA, 2015a; DURRANI, PICA, 2016)

Segundo a nota, a segunda etapa dos trabalhos pautaria maiores oportunidades de investimentos (tal como a negociação dos títulos da dívida de longo e curto prazo) e também derivativos, ou seja, que as negociações em marcados locais pudessem ocorrer através do MILA (MILA, 2015a).

A partir da Cúpula de Paracas, em julho de 2015, iniciaram-se os trabalhos conjuntos entre a Aliança do Pacífico e o MILA, em que cada instituição incluiria a outra em sua agenda de trabalho. Nesta Cúpula, os presidentes destacaram a necessidade de avançar em certos tópicos na área de movimento de capitais: conclusão do estudo para identificação de boas práticas para a atração de investimentos; finalização da avaliação de barreiras e oportunidades para o investimento nos países da Aliança do Pacífico; elaboração de projetos que contribuam para melhorar o ambiente de investimento e o comércio de serviços nos países membros (ALIANZA DEL PACÍFICO, 2015).

Os ministros de finanças foram instruídos a incluir a consolidação do MILA na agenda de trabalho para o período de 2015-2016, priorizando os aspectos de reconhecimento de emissores de ofertas, ampliação de novos instrumentos suscetíveis de negociação dos mercados em plataformas de intercâmbio distintas, ampliação do MILA aos mercados de renda fixa e derivativos padronizados, homologação do tratamento tributário e reconhecimento de investimento local dos fundos de pensões da região ${ }^{15}$.

Em contrapartida, o Comitê Executivo do MILA (composto pelos presidentes das Bolsas de Valores de cada país ${ }^{16}$ ) tomou a decisão de auxiliar em assuntos técnicos do Conselho de Ministros de Finanças da Aliança do Pacífico para consolidar e fortalecer o bloco em busca de benefícios gerais para as economias e mercados de capitais na região. Houve concordância que os emissores de ofertas primárias e a ampliação dos instrumentos de negociação seriam avaliados como parte de uma nova etapa de integração desses mercados. Também afirmaram que seria incorporado o compromisso declarado pelo Conselho da Aliança do Pacífico à planificação estratégica do MILA, tal como a implementação de políticas macroeconômicas e financeiras necessárias para adotar melhores práticas a nível estrutural e institucional, de maneira

\footnotetext{
14 Disponivel em: http://www.mercadomila.com/home/quienessomos. Acesso em: 06 jun. 2017.

15 Disponivel em: http://www.andina.com.pe/agencia/noticia-mila-profundizara-integracion-propuesta-mandatarios-alianza-delpacifico-564775.aspx. Acesso em: 24 ago. 2017.

${ }^{16} \mathrm{Não}$ foram encontradas informações adicionais sobre a estrutura institucional do MILA.
} 
conjunta com os reguladores de mercados financeiros e de capitais, no sentido de homologar o tratamento fiscal previsto nos acordos para evitar a dupla tributação (MILA, 2015b).

\section{Considerações Finais}

Neste trabalho, buscou-se fazer um breve apanhado dos objetivos e trajetória da Aliança do Pacífico, especialmente na questão financeira, e como o MILA pode contribuir com o objetivo primordial do bloco de alcançar a livre circulação de capitais.

Parte-se da definição de integração proposta por Haas (1958) e Balassa (1961), as contribuições de Biancareli (2009) e Martins (2016), e da trajetória dos regionalismos na América Latina, com foco na noção de regionalismo aberto (CEPAL, 1994), reiterada nos documentos da Aliança do Pacífico, que atribui ao mercado o papel principal na condução das políticas regionais.

Constata-se que a Aliança do Pacífico, ao longo de seis anos de existência, não criou uma instância supranacional para discutir os temas de interesse, como preveem as teorias de integração econômica ou integração financeira regional, mas se vinculou a outra instituição já existente em relação à integração financeira. Esta decisão decorre da reafirmação do MILA na agenda da Aliança do Pacífico, vistos nos documentos finais de Cúpulas Presidenciais.

Ainda que o MILA crie um mercado regional com o propósito de aproximar as Bolsas de Valores, esta decisão não significa que o processo de integração financeira vá em direção à unificação daquelas, pois mantém a autonomia e a autoridade no processo de integração das bolsas de valores do MILA; ou seja, não implica a integração societária das mesmas. Desta forma, o processo de integração financeira na Aliança do Pacífico está de acordo com a visão de integração econômica e política suscitada pelo bloco, e também do regionalismo aberto, no sentido de promover a abertura e desregulamentação do Estado. De maneira mais ampla, esse processo de integração corrobora com a literatura acadêmica sobre o regionalismo latino-americano ser marcado pelo rechaço às instâncias supranacionais de caráter decisório.

A efetivação da BMV ao MILA teve como desdobramento importante a cooperação entre aquele e a Aliança do Pacífico, de forma a reconhecer o trabalho do outro e a incluir em suas agendas de trabalho a adoção de políticas macroeconômicas e financeiras necessárias para adotar melhoras práticas a nível estrutural e institucional de maneira conjunta com os reguladores de mercados financeiros e de capitais ou seja, uma integração baseada na eliminação de barreiras entre as partes.

Outro aspecto positivo da incorporação do BMV ao MILA foi consolidá-la como a maior plataforma bursátil da região, com uma capitalização de bolsas de 940 bilhões de dólares e mais de 740 empresas negociadas, superando a Bovespa (DURRANI, PICA, 2016).

O MILA, de maneira geral, tem contribuído para o estreitamento de laços entre as instituições financeiras e, consequentemente, para que se avance no objetivo da Aliança do Pacífico de promover e 
atrair maior fluxo de capital para os países da região, no sentido de avançar na livre-circulação de capitais, um objetivo anunciado na primeira Cúpula em 2011.

* Artigo recebido em 16 nov 2017, aprovado em 01 mar 2018.

\section{REFERÊNCIAS}

ALAMOS, Sandoval; VÁSOUEZ-PÁRRAGA, Arturo; ARRIAGADA, Rocío. Integración de los Mercados Accionarios de Chile, Colombia y Perú en el Mercado Integrado Latinoamericano (MILA). Innovar, v. 25, p. 71-84, 2015.

ALIANZA DEL PACÍFICO. Acuerdo Marco. 2012. Disponível em: <alianzapacifico.net>. Acesso: 04 nov. 2017.

. Declaración de Lima. 2011a. Disponível em: <alianzapacifico.net/

documentos>. Acesso: 04 nov. 2017.

. Declaración de Mérida. 2011b. Disponível em: <alianzapacifico.net/

documentos>. Acesso: 04 nov. 2017.

. Declaración de Punta Mita. 2014. Disponível em: <alianzapacifico.net/

documentos>. Acesso: 04 nov. 2017.

. Declaración de Paracas. 2015. Disponível em: <alianzapacifico.net/

documentos>. Acesso: 04 nov. 2017.

Estructura y Organigrama. 2018. Disponível em: < http://alianzapacifico.net/que-es-laalianza/\#estructura-y-organigrama>. Acesso: 23 fev. 2018.

ÁLVAREZ, Mariano. Los 20 años de Mercosul: una integración a dos velocidades. Comercio Internacional - CEPAL, n. 108, p. 5-57, 2011.

BALASSA, Bela. The Theory of Economic Integration. London: Allew and Unwin, 1961.

BIANCARELI, André. The financial dimension of South American Integration: an assessment of the initiatives and a tentative quantification. Disponível em: 
http://www.eco.unicamp.br/cecon/images/arquivos/eventos/coloquio20og/ColoquioBr-FrAndre.ppt.

Acesso em: 26 fev. 2018.

BRICEÑO RUIZ, José. O Regionalismo Latino-Americano depois do Regionalismo Aberto: Novos Eixos, Novas Estratégias, Modelos Diversos. In: CARMO, C et al (Org.). Relações Internacionais: olhares cruzados. Brasília: Fundação Alexandre de Gusmão, 2014.

BUELVAS, Eduardo; VÉLEZ, Ricardo.; ALEGRÍA, Rafael. Colombia y la Alianza del Pacífico: um proyecto regional de cara a la multipolaridad creciente. In: BUELVAS, Eduardo; GEHRING, Hubert. Alianza del Pacífico: mitos y realidades. Bogotá: Pontificia Universidad Javeriana, 2014.

CARVALHO, Carlos et al. Banco do Sul: a proposta, o contexto, as interrogações e os desafios. In: VADELL, Javier; CAMPOS, Taiane (Org.). Os novos rumos do regionalismo e as alternativas políticas na América do Sul. Belo Horizonte: Editora da PUC-MG, 2010.

CEPAL. El Regionalismo abierto en América Latina y el Caribe: la integración económica al servicio de la transformación productiva con equidad. Santiago de Chile, 1994.

CORREDOR, Germán; VÉLEZ, Ricardo. Entre la soberanía, el liberalismo y la innovación: un marco conceptual para el análisis de la Alianza del Pacífico. In: BUELVAS, Eduardo; GEHRING, Hubert. Alianza del Pacífico: mitos y realidades. $1^{\text {a }}$ ed. Bogotá: Pontificia Universidad Javeriana, 2014.

DURRANI, Kassim; PICA, Jonathan. Market liquidity and the Latin American Integrated Market (MILA). In: JARRÍN, Mario; PICA, Jonathan (Org.). The Pacific Alliance: perspectives and opportunities for Latin America. Salamanca: European Institute of International Studies, 2016.

FARHI, Maryse; CINTRA, Marcos Antonio. O crash de 2002: da "exuberância irracional" à "ganância infecciosa". Revista de Economia Política, v. 23, n. 1, p. 39-61, 2003.

GUILLERMO, Perry. Financial Integration in the Pacific Alliance. Banco Interamericano de Desenvolvimento, 2016.

GUTTMANN, Robert. Uma introdução ao Capitalismo dirigido pelas finanças. Novos Estudos, n. 8o, p. 11 $-33,2008$.

HAAS, Ernest. The uniting of Europe: political, social, and economic forces 1950-1957. Notre Dame: University of Notre Dame Press, 1958.

HENDLER, Bruno. Correntes Políticas e Processos de integração na América Latina: A Aliança do Pacífico em comparação ao Mercosul e à ALBA. Revista Eletrônica de Ciência Política, Curitiba, vol. 6, n. 2, p.222 239, 2015 .

HERZ, Monica; HOFFMANN, Andrea Ribeiro. Organizações Internacionais: histórias e práticas. Rio de Janeiro: Elsevier: Campus, 2004. 
LERAUL, Daniel. Trading with Neighbors: Regional Stock Exchange Integration-The Mercado Integrado Latinoamericano. Latin American Business Review, n. 17, v.1, p. 49-71, 2016.

MARTINS, Norberto. Integração Financeira na América Latina entre 2000 e 2014: avanços, limites e caminhos à frente. IE-UFRJ DISCUSSION PAPER, n. 15, p. 1-63, 2016.

MARIANO, Karina. Nova Visão das Teorias de Integração Regional: Um Modelo para a América Latina. Relatório de Pesquisa (FAPESP). 2004.

MILA. Reseña Historia. Disponível em: http://www.mercadomila.com/home/resena. Acesso em: 23 ago. 2017.

S\&P MILA Pacific Alliance Indices Launched by S\&P Dow Jones Indices. 2014. Disponível em: www.mercadomila.com/home/comunicados. Acesso em: 06 nov. 2017.

Mila celebra cuatro años y plantea nuevos desafíos. 2015a. Disponível em: www.mercadomila.com/home/comunicados. Acesso em: 06 nov. 2017.

Mila profundizará Agenda de Integración financiera propuesta por jefes de Estado de la Alianza del Pacífico. 2015b. Disponível em: www.mercadomila.com/home/comunicados. Acesso em: 06 nov. 2017.

MINISTÉRIO DAS RELAÇÕES EXTERIORES. Mercosul. Disponível em: http://www.itamaraty.gov.br/ptBR/politica-externa/integracao-regional/686-mercosul. Acesso em: o6 fev. 2018.

PATRÍCIO, Raquel. Aliança do Pacífico: modelo alternativo de integração na América Latina. Janus, p, 142 - 2016.2 Disponivel em: <http://janusonline.pt/images/anuario2015/3.21_RaquelPatricio_AliancaPacifico.pdf>. Acesso em: 08 fev. 2018.

PORRAS, Eduardo. China y la Alianza del Pacífico: los limitantes de los roles en el proceso de construcción mutua. In: BUELVAS, Eduardo; GEHRING, Hubert. Alianza del Pacífico: mitos y realidades. $1^{\text {a }}$ ed. Bogotá: Pontificia Universidad Javeriana, p. 403-431, 2014.

RIGIROZZI, Pia; TUSSIE, Diana. The rise of post-hegemonic regionalism in Latin America. IN: RIGIROZZI, Pia; TUSSIE, Diana (Org.) The rise of post-hegemonic regionalism: the case of Latin America. $1^{\text {a }}$ ed. Dordrecht: Springer, 2012.

SANAHUJA, José. Regionalismo e integración en América Latina: de la fractura Atlántico-Pacífico a los retos de una globalización en crisis. Pensamiento Propio, n. 44, p. 29-76, 2017.

. Del "regionalimo abierto" al regionalismo "post-liberal". Anuario de Integración de América Latina y el Gran Caribe, v. 7, 2009.

SERBíN, Andrés. Introducción. Anuario de Integración de América Latina y Caribe, v. 10, 2014. 
SERRANO, Lorena; GALARRETA, Federico. La Alianza del Pacífico en América Latina: Contrapeso regional? Cuadernos sobre Relaciones Internacionales, Regionalismo y Desarrollo, n. 16, v. 8, jul/dez 2013.

SOUZA-SANTOS, Elson. As políticas de integração sul-americana e a cooperação financeira. Revista Economia \& Tecnologia, v. 9, n. 2, p. 31-41, 2013.

TABÍO, Luis René. La Alianza Transpacífico en la estrategia de Estados Unidos para América Latina y Caribe. Anuario de Integración de América Latina y Caribe, v. 10, 2014.

VEIGA, Pedro; RIOS, Sandra. O regionalismo pós-liberal na América do Sul: origens, iniciativas e dilemas. CEPAL Serie Comercio Internacional, n. 88, 2007. 